\title{
Occupational Risk of Hepatitis B Virus Exposure: Overview and Recommendations
}

\author{
Nader A. Nemr', Rania M. Kishk ${ }^{2 *}$, Mohamed A. Mandour ${ }^{3}$, Mostafa M. \\ Ragheb $^{1}$
}

Departments of ${ }^{1}$ Endemic and Infectious Diseases, ${ }^{2}$ Microbiology and Immunology, ${ }^{3}$ Clinical Pathology, Faculty of Medicine, Suez Canal University, Egypt

\begin{abstract}
Hepatitis B Virus has been recognized as an important occupational risk for health-care personnel (HCP) as the virus remains infectious for prolonged periods on environmental surfaces and is transmissible even in the absence of visible blood. Health care personnels (HCPs) who are in contact with blood or body fluids should be vaccinated against hepatitis $B$. HepB vaccine should administered intramuscularly into the deltoid muscle on a 0,1 , and 6-month schedule followed by HBsAb titre measurement. The protective level of anti-HBs should be $\geq 10 \mathrm{mlU} / \mathrm{mL}$. Booster doses of hepatitis B vaccine are not necessary, and periodic serologic testing to monitor antibody concentrations after completion of the vaccine series is not recommended. Hepatitis B immune globulin (HBIG) provides passive anti-HBs and temporary protection lasts for 3-6 months and can be used together with HepB vaccine for postexposure prophylaxis. Vaccinated HCPs who have written documentation of a complete HepB vaccine series ( $\geq 3$ doses) with documented anti-HBs $\geq 10 \mathrm{mlU} / \mathrm{mL}$, are immune and not in need for specific post exposure measures for HBV, whatever the source patient's HBsAg status.
\end{abstract}

Key words: Hepatitis B virus, HBsAg, HbsAb, vaccination, Post-exposure prophylaxis

\section{Introduction}

Hepatitis B virus (HBV) is a Blood Borne Pathogen (BBP) that is transmitted via blood or body fluids exposure as well as sexual $\operatorname{contact}^{(1)}$. HBV has been recognized as an occupational risk for healthcare personnel (HCP) as the virus remains infectious for prolonged periods on environmental surfaces and is transmissible even in the absence of visible blood. This explains the rising prevalence of HBV infection 10 times greater than general population as reported by $C D C$ in serologic studies conducted in the United States during the $1970 \mathrm{~s}^{(2)}$. In contrast to the transmission risk of HIV and HCV after a percutaneous exposure $(0.3 \%, 1.8 \%$ respectively), the risk of $\mathrm{HBV}$ transmission usually reaches 6 to $30 \%(3)$. HBV is a wellrecognized risk among $\mathrm{HCP}$ dealing with blood and blood products. Prevalence rates of HBV infection have been reported as 13 to $18 \%$ among surgeons. Infection rates up to $27 \%$ have been demonstrated among dentists and oral surgeons $(4,5)$. 
Avoiding occupational blood exposures is the primary way to prevent transmission of BBPs in health-care settings ${ }^{(6)}$. However, despite the improved methods of preventing exposure and occupational exposures, transmission of at least 20 different pathogens by needlestick and sharps injuries has been reported $(7)$. Yet, hepatitis $B$ immunization and post exposure management are integral components of a complete program to prevent infection following BBPs exposure and are both important components of workplace safety ${ }^{(8)}$. Hepatitis $B$ virus infection is a preventable disease with the Hep $B$ vaccination being available in the United States since 1981 and recommended by the Advisory Committee on Immunization Practices (ACIP) for HCP in $1982^{(9)}$. Acute and chronic HBV infections are rare among $\mathrm{HCP}$ who respond to HepB vaccination, but HCP who do not respond to vaccination are thought to remain susceptible. Since 1982 (when HepB vaccine was recommended for HCP by ACIP), major declines have occurred in reports of acute hepatitis B among $\mathrm{HCP}^{(10)}$. In 1991, ACIP recommended post vaccination serologic testing for anti-HBs for HCP at risk for needlestick exposures ${ }^{(11)}$. No postvaccination serologic testing is recommended after routine infant or adolescent HepB vaccination $^{(10)}$. In 1997, ACIP recommended postvaccination serologic testing 1-2 months after completion of the HepB vaccine series (3 doses of Hep $B$ vaccination) for HCP who have contact with patients' blood or body fluids and who are in risk for needlestick injuries (12). In 2011, ACIP recommended postvaccination serologic testing 1-2 months after completion of the vaccine series for $\mathrm{HCP}$ at high risk. The fact that the vaccine-induced anti-HBs wanes over time, testing HCP for anti-HBs years after vaccination might not distinguish vaccine nonresponders from responders ${ }^{(13)}$.

\section{HBV Background}

\section{HBV structure and replication}

Baruch Blumberg discovered the Australia antigen when searching for immunological evidence of genetic polymorphisms supposed that antibodies to blood proteins could be used to investigate human genetic diversity in patient's serum that had been exposed to multiple repeated transfusions ${ }^{(14,15)}$. By 1967, Blumberg and others discovered that Australia antigen was associated with hepatitis, then in 1970 Australia antigen was identified as a structural component of the hepatitis $B$ virus (HBV). That year (1970) Dane and coworkers published electron micrographs of 17-22 nm spherical HBV surface antigen (HBsAg) particles, 17-22 nm diameter filamentous HBsAg particles, and $45 \mathrm{~nm}$ diameter virions comprised of a $\mathrm{HBsAg}$ envelope and a $36 \mathrm{~nm}$ diameter core, HBV virions are known as Dane particles ${ }^{(16)}$. $\mathrm{HBV}$ is a double-stranded, enveloped DNA Hepadna virus ( $\sim 42$ to $47 \mathrm{~nm}$ ), which replicates in the liver. It is the smallest DNA virus known that consists of a viral envelope, nucleocapsid and a single copy of the partially double-stranded DNA genome. The viral genome has only $3200 \mathrm{bp}$ which is uniquely organized in partial circular dsDNA which contains a minusstrand (full genome) and a plus-strand of $D_{N A}{ }^{(17)}$. The surface/pre-S gene encodes for the virus envelope in which the major protein that forms the HBsAg particles is the smallest gene product (SHBs). The middle protein (MHBs), including the preS2 component, and the large surface protein (LHBs), which contains pre-S1, all are also integrated into HBsAg particles ${ }^{(18)}$. It is suggested that the pre-S proteins play an important role in the attachment of HBV to hepatocytes ${ }^{(18)}$. Pre-S1 and pre-S2 have been identified in vitro for liverspecific attachment sites(19-21). Once HBV attaches to liver cells, they become un- 
coated. The partially double-stranded viral genome is transformed in the nucleus, to covalently closed circular DNA (cccDNA). This cccDNA serves as template for all viral transcripts, including four mRNA transcripts of known function. The longest (3.5 kb) pregenomic RNA is the template for genome replication and the expression of precore/core and polymerase proteins. A 2.4-kb transcript encodes pre-S1, pre-S2, and $\mathrm{HBsAg}$, while a 2.1-kb transcript encodes only pre-S2 and HBsAg. The smallest transcript ( $0.7 \mathrm{~kb}$ ) encodes the $\mathrm{X}$ protein ${ }^{(17)}$. HBCAg and HBeAg are translated from one gene. After transcription, $\mathrm{HBCAg}$ is targeted to the endoplasmic reticulum where it is cleaved, and $\mathrm{HBeAg}$ (the precore fragment) is released. $\mathrm{HBcAg}$ a fundamental part of the nucleocapsid is central for viral assembly and is never detected in serum by conventional techniques; however, detection is possible in liver tissue samples from acute or chronic HBV infected patients. HBeAg is a soluble protein that can be detected in the serum of patients with high virus titers; it is not essential for viral replication ${ }^{(18)}$.

\section{Epidemiology of HBV infection}

It is estimated that approximately two billion people worldwide have evidence of past or present infection with $\mathrm{HBV}$, and 248 million individuals are chronic carriers (22, 23). In 2015, CDC reported a total of 3,370 cases of acute HBV infection while actual number of acute cases is believed to be 6.5 times the number of reported cases per year due to under-ascertainment and under-reporting(24). Generally, the prevalence of $\mathrm{HBsAg}$ is around $3.6 \%$; however, this varies depending upon the geographic area. In low-prevalence areas (e.g., United States, Canada, Western Europe), the prevalence of chronic HBV may be less than $<2 \%$. The prevalence may reach to $2-7 \%$ in intermediate-prevalence areas (e.g., Mediterranean countries, Ja- pan, Central Asia, Middle East, and parts of South America) and $\geq 8$ percent in highprevalence areas (e.g., Western Africa, South Sudan) ${ }^{(22,23)}$. These differences in geographic distribution of HBV infection may be related to differences in the age at infection, which is inversely related to the risk of chronicity ${ }^{(25)}$. The progression from acute to chronic HBV infection usually occur in $90 \%$ of infants, $30 \%$ of children aged $<5$ years, and $<1 \%-12 \%$ of adults $^{(26)}$. In Egypt, the prevalence of HBV ranges between $2 \%$ and $6 \%$ with the predominance of infection with HBV genotype $D^{(27)}$. It is widely known that Egypt is one of the countries with highest prevalence rate of infection with HCV in the world ${ }^{(28-31)}$.

\section{HBV transmission}

HBV is highly infectious, it can be transmitted in the absence of visible blood, and remains infectious on environmental surfaces for at least 7 days $(32,33)$. The virus can be transmitted through percutaneous injuries, mucosal, or nonintact skin exposure to infectious blood or body fluids. Blood (as a body fluid) contains the highest concentration of HBV virus, and percutaneous exposure is an efficient mode of transmission. Cerebrospinal fluid, synovial fluid, pleural fluid, peritoneal fluid, pericardial fluid, and amniotic fluid are considered potentially infectious ${ }^{(2)}$. Urine, feces, vomitus, nasopharyngeal washings, sputum, and sweat are not efficient vehicles of transmission unless they contain blood(33). Semen and vaginal secretions are infectious and can transmit HBV infection sexually. HBV is transmitted efficiently by sexual contact both among heterosexuals and among homosexual men. HBV also can be detected in saliva, tears, and bile ${ }^{(2)}$. HBsAg found in breast milk is also unlikely to lead to transmission, and hence $\mathrm{HBV}$ infection is not a contraindication to breast-feeding(32, 33). Transmission can occur from interpersonal contact with shar- 
ing the same instruments (e.g. toothbrush or razor) or contact with exudates from dermatologic lesions. HBV intra-familial transmission and spread has been reported. Three patterns of HBV intra-familial transmission were determined; maternal, paternal, and spousal(34). The viral transmission from transfusion of blood or blood products is rare because of the routine donor screening and viral inactivation procedures. Other possible sources of infection include contaminated medical or dental instruments, unsafe injections, needle-stick injuries, organ transplantation, and dialysis(35).

\section{Occupational transmission of HBV:}

The presence of HBsAg is an indicator of active infection. Hepatitis $B$ e antigen (HBeAg) is a marker for high HBV replication and infectivity(36). The risk for acquiring HBV infection is particularly high in occupational exposures to blood or body fluids from source patients who are positive for both $\mathrm{HBsAg}$ and $\mathrm{HBeAg}(3)$. Although testing occupational exposure source patients for HBeAg is not practical and is not recommended, the risk for developing clinical hepatitis if the blood was both HBsAg and HBeAg-positive was $22 \%-$ $31 \%$; the risk for developing serologic evidence of HBV infection was $37 \%-62 \%(2,3)$. By comparison, the risk for developing clinical hepatitis from a needle contaminated with HBsAg-positive, HBeAgnegative blood was $1 \%-6 \%(2)$. The most efficient method for occupational transmission of HBV is percutaneous injuries. Selection of blood donors depends on a screening system excluding the subjects that are positive for $\mathrm{HBsAg}$, anti-HCV, antiHIV and anti-treponema antibody. Despite the importance of anti-HBc screening for safer blood transfusion, this serological marker is not included in Egyptian blood bank screening. Then, such screening system in Egypt would miss occult HBV infec- tion (OBI) among blood donors (37, 38). Data since 2002 indicate that $18 \%$ of HCP trainees sustain a percutaneous exposure annually, and $54 \%$ of percutaneous exposures are reported to occupational health(39-43). Reluctance to report occupational percutaneous injuries may be due to fear of missing the job or concerns regarding $\operatorname{privacy}^{(40,42)}$.

\section{Recommendations for pre expo- sure management}

Exposure prevention remains the primary prophylactic strategy for reducing occupational injuries and transmission of BBPs. Written protocols for reporting, evaluation, counseling, treatment, and follow-up of occupational exposures should be available in the health care facilities. At the time of hire, HCPs should be well trained about safe injection, BBPs and PEP to improve recognition and encourage timely reporting of blood and body fluid exposures. The possibility that the post exposure evaluation will cause the HCP to have time lost from work should not be a barrier to reporting. Institutions should ensure that HCP have rapid access to post exposure testing and prophylaxis, including HBIG and HepB vaccine. In 1995, the CDC's Hospital Infection Control Practices Advisory Committee (HICPAC) introduced the concept of standard precautions, which apply to blood; all body fluids, secretions, and excretions (except sweat); non intact skin; and mucous membranes $^{(43)}$. The core elements of standard precautions contain (i) hand washing after patient contact, (ii) the use of barrier precautions (e.g., gloves, gowns, and facial protection) to prevent mucocutaneous contact, and (iii) minimal manual manipulation of sharp instruments and devices and disposal of these items in puncture resistant containers $(44,45)$. Health care personnel who perform tasks involving con- 
tact with blood or body fluids should be vaccinated against hepatitis $B$. Pre vaccination serologic screening for previous infection is not indicated for persons being vaccinated because of occupational risk, unless the hospital or health-care organization considers screening costeffective $^{(46)}$

\section{HBV vaccination}

OSHA mandates HBV vaccination for HCPs within 10 days of initial assignment. HCP should complete the series before the potential for exposure with blood or body fluids, when possible ${ }^{(47)}$. Hepatitis $B$ vaccine consists of 10 or $20 \mu \mathrm{g}$ of recombinant $\mathrm{HBsAg}$ protein administered intramuscularly into the deltoid muscle on a 0,1 , and 6-month schedule. Exceptional schedule (including a 4-dose program at 0, 1, 2, and 12 months) is USA- approved for usual immunization for specific ages and vaccine formulations with ultimate rates of sero protection comparable to those obtained on a 0,1 , and 6-month schedule. If the vaccination series is interrupted after the first dose, the second dose should be administered as soon as possible with no restarted vaccination for HCP with an incomplete series. However, minimum dosing intervals between the first and second dose should be 1 month, 2 months between the second and third dose, and 4 months between the first and third dose. If only the third dose is delayed, it should be administered when convenient ${ }^{(36)}$. HCP lacking documentation of HepB vaccination should be considered unvaccinated or incompletely vaccinated and should receive additional doses to complete a documented HepB series. OSHA mandates that HCP who refuse HepB vaccination sign a declination statement ${ }^{(48)}$. After completion of HBV 3-doses vaccination series, HCP should be tested 1-2 months for anti-HBs ${ }^{(49)}$. The protective level of anti-HBs should be $\geq 10 \mathrm{mlU} / \mathrm{mL}$. HCP who do not respond to an initial 3-dose vaccine series (i.e., anti-HBs $<10 \mathrm{mlU} / \mathrm{mL}$ ) have a $30 \%-50 \%$ chance of responding to a second 3-dose series. Non-responder HCP to the first vaccine series should complete a second 3-dose vaccine series or be evaluated for HBsAg-positive. Revaccinated $\mathrm{HCP}$ should be retested at the completion of the second vaccine series (6 doses of $\mathrm{HBV}$ vaccines). A non-responder is defined as a person with anti-HBs $<10 \mathrm{mIU} / \mathrm{mL}$ after $\geq 6$ doses of HepB vaccine. Booster doses of hepatitis B vaccine are not necessary, and periodic serologic testing to monitor antibody concentrations after completion of the vaccine series is not recommended. Persons who do not have a protective concentration of anti-HBs after revaccination should be tested for HBsAg. If positive, the person should receive appropriate management and should be counseled regarding how to prevent HBV transmission to others. Non-responders to vaccination who are HBsAg-negative should be considered susceptible to HBV infection and should be counseled regarding precautions to prevent HBV infection. $\mathrm{HCP}$ who have written documentation of a complete, $\geq 3$-dose HepB vaccine series and subsequent postvaccination anti-HBs $\geq 10 \mathrm{mlU} / \mathrm{mL}$ are considered hepatitis $B$ immune. Immunocompetent persons have long-term protection against HBV and do not need further periodic testing to assess anti-HBs levels(50) (figure 1). AntiHBs levels after vaccination decline over time and the persistence of protective levels $(\geq 10 \mathrm{mlU} / \mathrm{ml}$ ) varies by age at vaccination. By 18 years after vaccination, approximately $16 \%$ of persons vaccinated at age $<1$ year have detectable antibody levels of $\geq 10 \mathrm{mIU} / \mathrm{mL}^{(51-53)}$, compared with $74 \%$ for those vaccinated at age $\geq 1$ year ${ }^{(54-57)}$. In a study of matriculating health science students, $92.9 \%$ of those who had received 3 doses of HepB vaccine had anti-HBs $\geq 10 \mathrm{mIU} / \mathrm{mL}^{(57)}$. HepB vaccines have been 
demonstrated to be safe among persons in all age groups. The most frequently reported side effects are pain at the injection site $(3-29 \%)$ and temperature of $>37.7^{\circ} \mathrm{C}(1-6 \%)$. HepB vaccination is contraindicated for persons with a history of hypersensitivity to yeast or any vaccine component as eggs. Persons with a histo- ry of serious adverse events (e.g., anaphylaxis) after receipt of $\mathrm{HepB}$ vaccine should not receive additional doses. The vaccine is safe for pregnant or lactating women as the available vaccines contain noninfectious HBsAg and do not pose a risk for infection to the fetus( ${ }^{(36)}$.

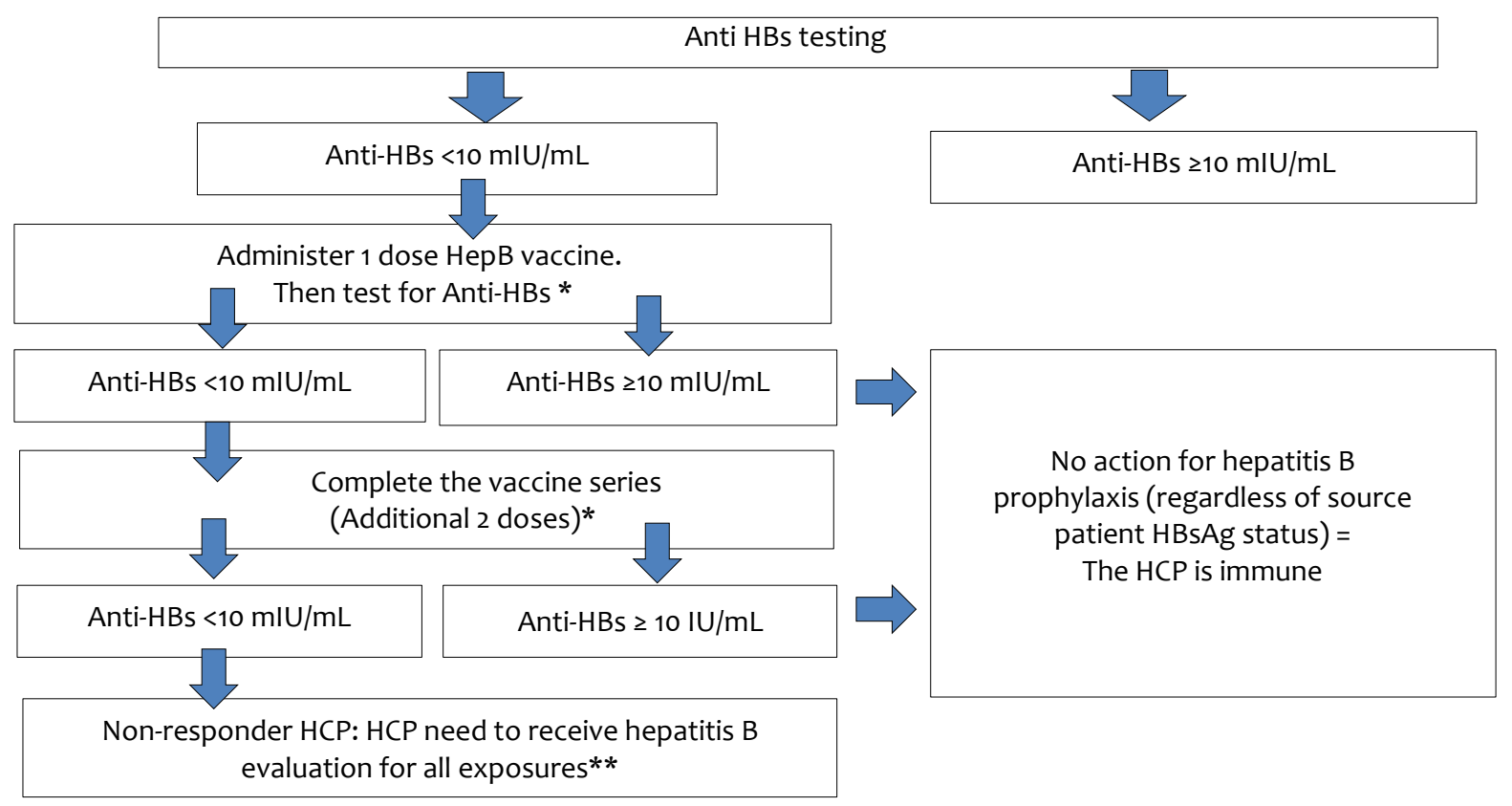

Figure 1: Pre-exposure evaluation for HCP previously vaccinated with complete, $\geq 3$-dose HepB vaccine series with no postvaccination serologic testing*

Adopted from CDC. A comprehensive immunization strategy to eliminate transmission of HBV in the US: recommendations of the Advisory Committee on Immunization Practices (ACIP). Part II: immunization of adults. MMWR 2006; 55 (No. RR-16). *Should be performed 1-2 months after the last dose of vaccine using a quantitative method that allows detection of the protective concentration of anti-HBs $(\geq 10 \mathrm{mlU} / \mathrm{mL}$ ) (e.g., enzyme-linked immunosorbent assay [ELISA]). ** A non-responder= a person with anti-HBs $<10 \mathrm{mlU} / \mathrm{mL}$ after $\geq 6$ doses of HepB vaccine. Persons who do not have a protective concentration of anti-HBs after revaccination should be tested for $\mathrm{HBsAg}$. If positive, the person should receive appropriate management.

\section{Post-exposure management (Fig. 2)}

Treatment of the exposure site: Wounds and skin sites that have been exposed to blood or body fluids should be washed with soap and water; mucous membranes should be flushed with water. Using antiseptics for wound care or squeezing fluid were not proven to diminish the risk of blood borne pathogen transmission; however, the use of antiseptics is not contraindicated. The application of caustic agents (e.g. bleach) or the injection of antiseptics or disinfectants into the wound is not recommended ${ }^{(58)}$.

Exposure Report: HCP should be trained well about the reporting process after occupational exposure to blood or body fluids. The exposure report is confidential and must contain date and time of exposure, details of the procedure being performed, and details of the exposure (i.e. type and amount of fluid or material and exposure severity). Exposure source, if known, and exposed HCP should be eval- 
uated and documented in the exposure report. Finally, details about counseling, post-exposure management, and follow- up must be written in the exposure report ${ }^{(58)}$.

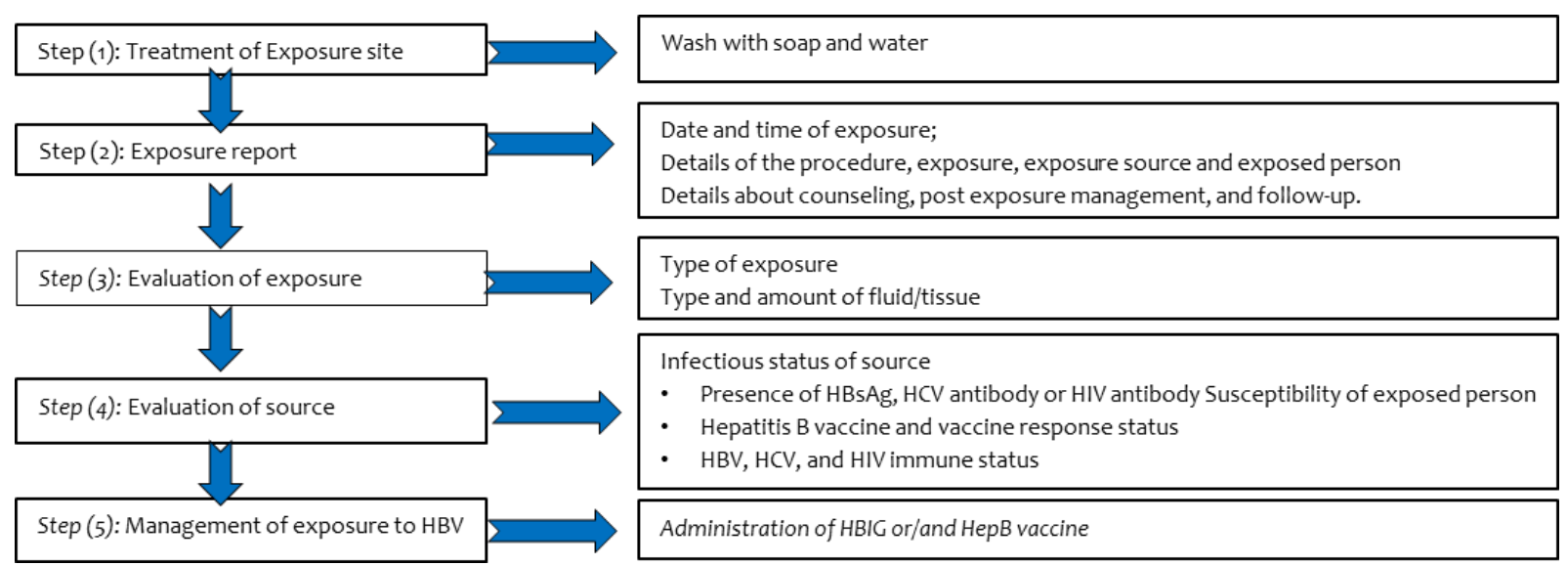

Figure 2: Post-exposure management after HBV exposure

Abbreviations: HBsAg: Hepatitis B surface antigen, HBV: Hepatitis B virus, HCV: Hepatitis C virus, HIV: Human Immunodeficiency virus, HBIG: Hepatitis B immunoglobulin, HepB vaccine: Hepatitis B vaccine

Evaluation of the exposure: The exposure should be evaluated for the potential to transmit HBV, HCV, and HIV based on the type of body substance involved and the route and severity of the exposure. Blood is considered the main body fluid containing high titre of HBV followed by fluids containing blood. Other probable infectious body fluids (semen; vaginal secretions; and cerebrospinal, synovial, pleural, peritoneal, pericardial, amniotic fluids and direct contact with concentrated virus) are considered a source of transmission of $\mathrm{BBP}^{(58)}$. Exposure to these fluids or tissue through a percutaneous injury (i.e., needlestick or other penetrating sharpsrelated event) or through contact with a mucous membrane or non-intact skin (dermatitis, open wound, and abrasions) is situations that pose a risk for BBP transmission and require further evaluation. In the clinical evaluation for human bites, possible exposure of both the person bitten and the person who inflicted the bite must be considered. If a bite results in blood exposure to either person involved, post exposure follow-up should be provid- ed(58)

Evaluation of the exposure source: Anyone whose blood or body fluid is the source of a work-related exposure should be evaluated for HBV, HCV, and HIV infection. Direct virus tests for usual screening of source patients are not suggested. Indeed, privacy of the source person should be preserved all the time. Testing to determine the HBV, HCV, and HIV infection status of an exposure source should be performed as soon as possible. If the source person is not infected with a BBP, baseline testing or further follow-up of the exposed person is not necessary. If the exposure source is unknown or can't be tested (e.g., the source person refuses testing), evaluate the likelihood of exposure to a source at high risk for infection. Testing discarded needles for BBPs is not recommended as testing might be hazardous to persons handling the sharp instrument.

Management of HBV exposure: HepB vaccine is available as a single-antigen formulation and in combination with other vaccines. Recombivax $\mathrm{HB}$ and Engerix- $\mathrm{B}$ are 
two single-antigen recombinant $\mathrm{HBsAg}$ vaccines are available in the United States. Twinrix is a licensed combination vaccine contains recombinant $\mathrm{HBsAg}$ and inactivated hepatitis $A$ virus and available for persons aged $\geq 18$ years(36). Hepatitis B immune globulin (HBIG) provides passive anti-HBs and temporary protection lasts for 3-6 months and can be used together with HepB vaccine for postexposure prophylaxis. HBIG is prepared from human plasma known to contain a high titer of anti-HBs. HBIG administered alone is the primary method of protection after HBV exposure in HCPs who are non-responder to HepB vaccine. The standard adult dose of $\mathrm{HBIG}$ is $0.06 \mathrm{~mL} / \mathrm{kg}$, by intramuscular injection and can be administered simultaneously with HepB vaccine but at a different injection site(36). Serious adverse effects from HBIG are rare including local pain and tenderness at the injection site, urticaria, and angioedema might occur. $\mathrm{HBIG}$ is not contraindicated for pregnant or lactating women ${ }^{(2)}$. Unvaccinated or incompletely vaccinated HCP who have anti$\mathrm{HBs}<10 \mathrm{mIU} / \mathrm{mL}$ and sustain a percutaneous, mucosal, or nonintact skin exposure to a source patient who is HBsAg-positive or has unknown HBsAg status should undergo baseline testing for HBV infection as soon as possible after the exposure, and follow-up testing approximately 6 months later. Testing immediately after the exposure should consist of total anti-HBc, and follow-up testing approximately 6 months later should consist of $\mathrm{HBsAg}$ and total anti-HBc${ }^{(2)}$. Health Care Personnel exposed to a source patient who is HBsAg-positive or has unknown HBsAg status do not need to take special precautions to prevent secondary transmission during the follow-up period (6 months). However, they should refrain from donating blood, plasma, organs, tissue, or semen. The exposed HCP does not need to modify sexual practices or refrain from becoming pregnant. If an exposed HCP is breast feeding, she does not need to discontinue ${ }^{(2)}$. Any blood or body fluid exposure to an unvaccinated person should lead to initiation of the hepatitis $B$ vaccine series. The hepatitis $B$ vaccination status and the vaccine-response status (if known) of the exposed person should be reviewed. A summary of prophylaxis recommendations for percutaneous or mucosal exposure to blood according to the HBsAg status of the exposure source and the vaccination and vaccine-response status of the exposed person is shown in table ${ }^{(1)}$. Health-care institutions should maintain records, ideally electronic records that are easily retrievable following exposures, of documented vaccination histories and serologic test results for reference in managing occupational exposures, and to provide to other health-care institutions if requested by the HCP.

\section{PEP management in vaccinated HCP}

Case (1): Vaccinated HCP who have written documentation of a complete HepB vaccine series ( $\geq 3$ doses) with subsequent documented anti-HBs $\geq 10 \mathrm{mlU} / \mathrm{mL}$, testing the source patient for HBsAg is unnecessary. No specific post exposure measures for HBV are needed, whatever the source patient's HBsAg status.

Case (2): Vaccinated HCP who have written documentation of HepB vaccination with anti$\mathrm{HBs}<10 \mathrm{mIU} / \mathrm{mL}$ after two complete vaccine series ( 6 doses), the source patient should be tested for HBsAg as soon as possible after the exposure. If the source patient is HBsAgpositive or has unknown HBsAg status, the HCP should receive 2 doses of HBIG. The first dose should be administered as soon as possible after the exposure, and the second dose should be administered 1 month later. If the source patient is HBsAg-negative, neither HBIG nor HepB vaccine is necessary ${ }^{(2,13)}$.

Case (3): Vaccinated HCP who have written documentation of a complete vaccine series without previous anti-HBs testing, the HCP should be tested for anti-HBs and the source patient (if known) should be tested for HBsAg as soon as possible after the exposure: If the 
source patient is HBsAg-positive or has unknown $\mathrm{HBsAg}$ status and the HCP has anti-HBs $<10 \mathrm{mlU} / \mathrm{mL}$, the HCP should receive 1 dose of $\mathrm{HBIC}$ and be revaccinated (3 doses) as soon as possible after the exposure. Anti-HBs testing should be performed 1-2 months after the last dose of vaccine and then document the HCP's vaccine response status. If the source patient is HBsAg-negative and the HCP has anti-HBs $<10 \mathrm{mlU} / \mathrm{mL}$, the HCP should receive an additional HepB vaccine dose, followed by repeat anti-HBs testing 1-2 months later. HCP whose anti-HBs remains $<10 \mathrm{mlU} / \mathrm{mL}$ should undergo revaccination with 2 more doses ( 6 doses total when accounting for the original 3-dose series). Anti-HBs testing should be performed 1-2 months after the last dose of vaccine and then document the HCP's vaccine response status. If the HCP has anti-HBs $\geq 10 \mathrm{mIU} / \mathrm{mL}$ at the time of the exposure, no postexposure HBV management is necessary, regardless of the source patient's HBsAg status.

\section{Unvaccinated or incompletely vaccinated HCP}

For unvaccinated or incompletely vaccinated HCP (including those who refused vaccination), the source patient should be tested for HBsAg as soon as possible after the exposure. Testing unvaccinated or incompletely vaccinated HCP for anti-HBs is not necessary and is potentially misleading, because anti-HBs $\geq 10 \mathrm{mlU} / \mathrm{mL}$ as a correlate of vaccine-induced protection has only been determined for persons who have completed an approved vaccination series $(36,59)$.

Case (4): If the source patient is HBsAg-positive or has unknown HBsAg status: The HCP should receive 1 dose of HBIG and 1 dose of HepB vaccine administered as soon as possible after the exposure. The HCP should complete the HepB vaccine series according to the vaccination schedule (3 doses total). Anti-HBs testing should be performed approximately 1-2 months after the last dose of vaccine to document the HCP's vaccine response status for future exposures. HCP with anti-HBs $\geq 10 \mathrm{mlU} / \mathrm{mL}$ after receipt of the primary vaccine series are considered immune. Immunocompe- tent persons have long-term protection and do not need further periodic testing to assess anti$\mathrm{HBs}$ levels. HCP with anti-HBs $<10 \mathrm{mIU} / \mathrm{mL}$ after receipt of the primary series should be revaccinated. For these $\mathrm{HCP}$, administration of a second complete 3-dose series on an appropriate schedule, followed by anti-HBs testing 1-2 months after the third dose, usually is more practical than conducting serologic testing after each additional dose of vaccine. To document the HCP's vaccine response status for future exposures, anti-HBs testing should be performed 1-2 mos. after last dose of vaccine.

Case (5): If the source patient is HBsAgnegative: The HCP should complete the HepB vaccine series according to the vaccination schedule. Anti-HBs testing should be performed 1-2 months after the last dose of vaccine to document the HCP's vaccine response status for future exposures. HCP with anti-HBs $\geq 10 \mathrm{mlU} / \mathrm{mL}$ after receipt of the primary vaccine series are considered immune. Immunocompetent persons have long-term protection and do not need further periodic testing to assess anti$\mathrm{HBs}$ levels. HCP with anti-HBs $<10 \mathrm{mIU} / \mathrm{mL}$ after receipt of the primary series should be revaccinated. For these HCP, administration of a second complete 3-dose series on an appropriate schedule, followed by anti-HBs testing 1-2 months after the third dose, usually is more practical than conducting serologic testing after each additional dose of vaccine. To document the HCP's vaccine response status for future exposures, anti-HBs testing should be performed 1-2 months after the last dose of vaccine

\section{HepB Vaccine Non responders}

Vaccinated HCP, who are non-responders, should be tested for $\mathrm{HBsAg}$ and anti-HBc to determine infection status. Those HCPs should be considered susceptible to HBV infection if hepatitis markers are negative. No specific work restrictions are recommended for vaccine non-responders ${ }^{(60)}$.

\section{Conclusion}

Avoiding occupational blood exposures is the primary way to prevent transmission of BBPs in health-care settings. Hep- 
atitis $B$ virus infection is a preventable disease with the Hep $B$ vaccination being available in the United States since 1981 and recommended by the Advisory Committee on Immunization Practices (ACIP) for HCP in 1982. Written protocols for reporting, evaluation, counseling, treatment, and follow-up of occupational exposures should be available in the health care facilities. Hepatitis $B$ vaccine consists of $10-20 \mu \mathrm{g}$ of recombinant $\mathrm{HBsAg}$ protein administered intramuscularly into the deltoid muscle on a 0, 1, and 6 mos. schedule. After completion of HBV 3-doses vaccination series, HCP should be tested 1-2 months for antiHBs. The protective level of anti-HBs should be $\geq 10 \mathrm{mlU} / \mathrm{ml}$. HCP who do not respond to an initial 3-dose vaccine series have a $30 \%-50 \%$ chance of responding to a second 3-dose series. Non-responder HCP to the first vaccine series should complete a second 3-dose vaccine series or be evaluated for HBsAg-positive. Hepatitis $B$ immune globulin ( $\mathrm{HBIG}$ ) provides passive anti-HBs and temporary protection lasts for 3-6 months and can be used together with HepB vaccine for postexposure prophylaxis. Any blood or body fluid exposure to an unvaccinated person should lead to initiation of the hepatitis $B$ vaccine series. Vaccinated HCP who have written documentation of a complete HepB vaccine series ( $\geq 3$ doses) with subsequent documented anti-HBs $\geq 10 \mathrm{mIU} / \mathrm{mL}$, testing the source patient for HBsAg is unnecessary. No specific post exposure measures for HBV are needed, whatever the source patient's $\mathrm{HBsAg}$ status. For unvaccinated or incompletely vaccinated HCP (including those who refused vaccination), the source patient should be tested for HBsAg as soon as possible after the exposure. Testing unvaccinated or incompletely vaccinated HCP for anti-HBs is not necessary and is potentially misleading, because anti-HBs $\geq 10 \mathrm{mIU} / \mathrm{mL}$ as a correlate of vaccine-induced protection has only been determined for persons who have completed an approved vaccination series. Vaccinated HCP, who are nonresponders, should be tested for $\mathrm{HBsAg}$ and anti-HBC to determine infection status. Those HCPs should be considered susceptible to HBV infection if hepatitis markers are negative.

\section{References}

1. CDC. Prevention of Hepatitis B Virus Infection in the United States: Recommendations of the Advisory Committee on Immunization Practices. MMWR January 12, 2018: 67(1);1-31

2. US Public Health Service. Updated U.S. Public Health Service guidelines for the management of occupational exposures to HBV, HCV, and HIV and recommendations for postexposure prophylaxis. MMWR 2001; 29:50 (No. RR-11).

3. Beltrami EM, Williams IT, Shapiro CN, et al. Risk and management of blood-borne infections in health care workers. Clin Microbiol Rev 2000; 13:385-407.

4. Smith JL, Maynard JE, Berquist KR, et al. Comparative risk of hepatitis $B$ among physicians and dentists. J. Infect. Dis. 1976:133:705-706.

5. West DJ. The risk of hepatitis B infection among health professionals in the United States: a review. Am. J. Med. Sci. 1984; 287:26-33

6. CDC. NIOSH alert: preventing needle stick injuries in health care settings. Cincinnati, $\mathrm{OH}$ : Department of Health and Human Services, CDC, 1999; DHHS publication no. (NIOSH) 2000-108.

7. Collins $\mathrm{CH}$, Kennedy DA. Microbiological hazards of occupational needle stick and 'sharps' injuries. J. Appl. Bacteriol. 1987,62:385-402

8. Dept. of Labor, Occupational Safety and Health Administration. 29 CFR Part 1910.1030. Occupational exposure to bloodborne pathogens; final rule. Federal Register 1991, 56:64004-182.

9. $\mathrm{CDC}$. Recommendation of the Immunization Practices Advisory Committee (ACIP). Inactivated hepatitis $B$ virus vaccine. MMWR 1982; 31:31722, 27-8.

10. CDC. Viral hepatitis statistics and surveillance. Available at http:// www.cdc.gov/ hepatitis/statistics/index.htm.

11. CDC. Update on adult immunization: recommendations of the ACIP. MMWR 1991; 40(RR-12).

12. $C D C$. Immunization of health-care workers: recommendations of the (ACIP) and the Hospital Infection Control Practices Advisory Committee. MMWR 1997; 46(No. RR-18). 
Table 1: post exposure prophylaxis recommendations after exposure to hepatitis B virus

\begin{tabular}{|c|c|c|c|}
\hline \multirow{2}{*}{ HCP status } & \multicolumn{3}{|c|}{ Source } \\
\hline & HBsAg positive & HBsAg negative & Unknown \\
\hline Unvaccinated & $\begin{array}{l}\text { HBIG }(1 \text { dose })^{\circledR} \\
\text { Start HepB vaccine series* }\end{array}$ & $\begin{array}{l}\text { Start HepB vaccine } \\
\text { series }\end{array}$ & $\begin{array}{l}\text { Start HepB vaccine } \\
\text { series }\end{array}$ \\
\hline $\begin{array}{l}\text { Documented responder } \\
\text { after complete series** }\end{array}$ & \multicolumn{3}{|c|}{ No action needed } \\
\hline $\begin{array}{l}\text { Non-responder }{ }^{* * *} \text { after } 1^{\text {st }} \\
\text { series ( } 3 \text { doses) }\end{array}$ & $\begin{array}{l}\text { HBIG (1 dose) } \\
\text { Start HepB vaccine } 2^{\text {nd }} \text { series }\end{array}$ & \multirow{2}{*}{ No action needed } & \multirow{2}{*}{$\begin{array}{l}\text { Manage as HBsAg } \\
\text { positive source }\end{array}$} \\
\hline $\begin{array}{l}\text { Non-responder after } 2^{\text {nd }} \\
\text { series ( } 6 \text { doses) }\end{array}$ & HBIG (2 doses) ${ }^{\circledR} \circledR$ & & \\
\hline $\begin{array}{l}\text { Unknown antibody re- } \\
\text { sponse after vaccine series }\end{array}$ & $\begin{array}{l}\text { Anti-HBs: } \\
\geq 10^{\#}: \text { no treatment } \\
<10^{\#}: \text { HBIG }(1 \text { dose })+\text { revaccina- } \\
\text { tion }\end{array}$ & $\begin{array}{l}\text { Test the exposed per- } \\
\text { son for anti-HBs: } \\
\geq 10^{\#}: \text { no treatment } \\
<10^{\#}: \text { revaccination }\end{array}$ & $\begin{array}{l}\text { Anti-HBs: } \\
\geq 10^{\#}: \text { no treatment } \\
\left.<10^{\#}: \text { HBIG ( } 1 \text { dose }\right)+ \\
\text { revaccination }\end{array}$ \\
\hline
\end{tabular}

Abbreviations: HCP: Health Care Personnel, HBsAg: Hepatitis B surface antigen, HepB vaccine: Hepatitis B vaccine, HBIG: Hepatitis B Immunoglobulin, anti-HBs: Antibody to Hepatitis B surface antigen, ${ }^{*} \mathrm{HepB}$ vaccine series $=3$ doses of vaccine at 0, 1, $6 \mathrm{~m}$ intervals in the deltoid region. ${ }^{* *} A$ responder= a person with anti-HBs $\geq 10 \mathrm{mIU} / \mathrm{mL}$ after complete series of hepatitis $B$ vaccine (3 doses or more). ${ }^{* * *} A$ non-responder= a person with inadequate response to Hepatitis $B$ vaccine (anti-HBs <10mlU/mL). ${ }^{\circledR}$ Hepatitis B immunoglobulin dose is $0.06 \mathrm{ml} / \mathrm{kg}$; ${ }^{\circledR}{ }^{\oplus}$ For HCP who previously completed $2^{\text {nd }}$ vaccine series but failed to respond, two doses of HBIG are preferred separated by 1-month interval. $\#=\mathrm{mIU} / \mathrm{mL}$

13. CDC. Immunization of health-care personnel: recommendations of the Advisory Committee on Immunization Practices (ACIP). MMWR 2011; 60 (No. RR-7).

14. Blumberg BS. Polymorphisms of the serum proteins and the development of iso-precipitins in transfused patients. Bull N Y Acad Med. 1964; 40:377-86.

15. Gerlich WH. Medical virology of Hepatitis B: how it began and where we are now. Virol J. 2013; 10:239.

16. Dane DS, Cameron CH, Briggs $M$. Virus-like particles in serum of patients with australiaantigen associated hepatitis. Lancet. 1970; 1(7649):695-98.

17. Lau JY, Wright TL. Molecular virology and pathogenesis of hepatitis B. Lancet1993, 342:133540.

18. Gerlich WH, Bruss V. Functions of hepatitis B virus proteins and molecular targets for protective immunity. (Marcel Dekker, Inc. New York) 1993.

19. Gerlich WH, Lu X, Heerman KH. Studies on the attachment and penetration of hepatitis $B$ virus. J. Hepatol. 1993; 17:S10-S14.

20. Neurath AR, Kent SB, Strick N, et al. Identification and chemical synthesis of a host cell receptor binding cite on hepatitis B virus. Cell 1986; 46:429-436.

21. Pontisso P, Petit MA, Bankowski MJ, et al. Human liver plasma membranes contain receptors for the hepatitis B virus pre-s1 region and, via polymerized human serum albumin, for the pre-s2 region.J. Virol. 1989; 63:1981-1988

22. Ott JJ, Stevens GA, Groeger J, et al. Global epidemiology of hepatitis $B$ virus infection: new estimates of age specific HBsAg seroprevalence and endemicity. Vaccine 2012; 30:2212.
23. Schweitzer A, Horn J, Mikolajczyk RT, et al. Estimations of worldwide prevalence of chronic hepatitis B virus infection: a systematic review of data published between 1965 and 2013. Lancet 2015; 386:1546.

24. CDC. Viral hepatitis-statistics and surveillance. Atlanta, GA: US Department of Health and Human Services, 2017. https://www.cdc.gov/hepatitis/statistics/

25. Zhang Q, Qi W, Wang X, et al. Epidemiology of Hepatitis B and Hepatitis C Infections and Benefits of Programs for Hepatitis Prevention in Northeastern China: A Cross-Sectional Study. Clin Infect Dis 2016; 62:305.

26. Hyams KC. Risks of chronicity following acute hepatitis B virus infection: a review. Clin Infect Dis 1995; 20:992-1000.

27. Zekri AR, Hafez MM, Mohamed NI, et al. Hepatitis $B$ virus (HBV) genotypes in Egyptian pediatric cancer patients with acute and chronic active HBV infection. Virol J 2007; 4:74

28. El-Zayadi A, Selim O, Rafik M, el-Haddad S. Prevalence of hepatitis $C$ virus among non-A, non-B-related chronic liver disease in Egypt. J Hepatol 1992; 14:416-417.

29. Arthur RR, el-Sharkawy MS, Cope SE, et al. Recurrence of Rift Valley fever in Egypt. Lancet 1993;342:1149-1150.

30. El Gohary A, Hassan A, Nooman Z, et al. High prevalence of hepatitis $C$ virus among urban and rural population groups in Egypt. Acta Trop 1995; 59:155-161.

31. Kishk R, Nemr N, Elkady A, et al. Hepatitis B surface gene variants isolated from blood donors with overt and occult HBV infection in north eastern Egypt. Virol J. 2015; 30; 12:153.

32. CDC. Recommendation of the Immunization Practices Advisory Committee (ACIP). Inactivat- 
ed hepatitis $B$ virus vaccine. MMWR Morb Mortal Wkly Rep 1982; 31:317-22, 327-8.

33. Preboth M. PHS guidelines for management of occupational exposure to HBV, HCV and HIV: management of occupational blood exposures. Am Fam Physician 2001; 64:2012-4

34. Ragheb M, Elkady A, Tanaka Y, et al. Multiple intra-familial transmission patterns of hepatitis $B$ virus genotype $D$ in north-eastern Egypt. J Med Virol. 2012 Apr; 84(4):587-95.

35. Trépo $C$, Chan HL, Lok $A$. Hepatitis $B$ virus infection. Lancet 2014; 384:2053-63.

36. CDC. A comprehensive immunization strategy to eliminate transmission of hepatitis B virus infection in the United States: recommendations of the Advisory Committee on Immunization Practices (ACIP) part II: immunization of adults. MMWR 2006; 55(No. RR-16); quiz.

37. El-Sherif AM, Abou-Shady MA, Al-Hiatmy MA, et al. Screening for hepatitis $B$ virus infection in Egyptian blood donors negative for hepatitis $B$ surface antigen. Hepatol Int. 2007; 1:469-470. doi: 10.1007/s12072-007-9017-2.

38. Said ZN, Sayed MH, Salama II, et al. Occult hepatitis $B$ virus infection among Egyptian blood donors. World J Hepatol. 2013; 5:64-73.

39. Trinkoff AM, Le R, Geiger-Brown J, Lipscomb J. Work schedule, needle use, and needlestick injuries among registered nurses. Infect Control Hosp Epidemiol 2007; 28:156-64.

40. Boal WL, Leiss JK, Sousa S, et al. The national study to prevent blood exposure in paramedics: exposure reporting. Am J Ind Med 2008; 51:21322.

41. Gershon RR, Pearson JM, Sherman MF, et al. The prevalence and risk factors for percutaneous injuries in registered nurses in the home health care sector. Am J Infect Control 2009; 37:525-33.

42. Gershon RR, Qureshi KA, Pogorzelska M, et al. Non-hospital based registered nurses and the risk of bloodborne pathogen exposure. Ind Health 2007; 45:695-704.

43. Lipscomb J, Sokas R, McPhaul K, et al. Occupational blood exposure among unlicensed home care workers and home care registered nurses: are they protected? Am J Ind Med 2009; 52:56370.

44. Centers for Disease Control. 1987. Recommendations for prevention of HIV transmission in health-care settings. Morbid. Mortal. Weekly Rep.36 (2S):1S-18S.

45. CDC 1988. Update: universal precautions for prevention of transmission of HIV, HBV, and other blood borne pathogens in health-care settings. Morbid. Mortal.Weekly Rep. 37:377-382, 387-388.

46. CDC. Immunization of health-care workers: recommendations of the Advisory Committee on Immunization Practices (ACIP) and the Hospital
Infection Control Practices Advisory Committee. MMWR 1997;46(No. RR-18).

47. US Department of Labor. Occupational Health and Safety Administration. Available at http://www.osha.gov.

48. CDC. Healthy people topics and objectives index. Available at http:// www.healthy people.gov/2020/topicsobjectives2020/default.aspx.

49. CDC. National and state vaccination coverage among adolescents aged 13-17 years-United States, 2011. MMWR 2012; 61:671-7.

50. Hadler SC, Francis DP, Maynard JE, et al. Longterm immunogenicity and efficacy of hepatitis $B$ vaccine in homosexual men. N Engl J Med 1986; 315:209-14.

51. Dentinger $\mathrm{CM}$, McMahon $\mathrm{BJ}$, Butler $\mathrm{JC}$, et al. Persistence of antibody to hepatitis $B$ and protection from disease among Alaska natives immunized at birth. Pediatr Infect Dis J 2005; 24:786-92.

52. Hammitt LL, Hennessy TW, Fiore $A E$, et al. Hepatitis $B$ immunity in children vaccinated with recombinant hepatitis $B$ vaccine beginning at birth: a follow-up study at 15 years. Vaccine 2007; 25:6958-64.

53. Middleman AB, Baker C, Hu DJ, et al. Duration of immunity from hepatitis $B$ vaccine administered soon after birth among 16 to 19-year-old youth in the United States. Presented to the Pediatric Academic Societies, Boston, MA, 29, 2012.

54. Advisory Committee on Immunization Practices. Reilly M. Evidence for cost-effectiveness analysis: non-cost related model inputs. Atlanta, Georgia: CDC; 2012. Available at http://www.cdc.gov/vaccines/acip/ meetings/downloads/min-archive/min-jun12.pdf.

55. Funderburke PL, Spencer L. Hepatitis B immunity in high risk health care workers. Seven years post vaccination. AAOHN J 2000; 48:325-30.

56. McMahon B, ed. 30-year follow-up after HBV vaccination in adults and children. Technical Viral Hepatitis Prevention Board meeting; Italy; 2011.

57. Spradling PR, Williams RE, Xing J, et al. Serologic testing for protection against hepatitis $B$ virus infection among students at a health sciences university in the United States. Infect Control Hosp Epidemiol 2012; 33:732-6.

58. CDC. Updated US. Public Health Service Guidelines for the Management of Occupational Exposures to HBV, HCV, and HIV and Recommendations or Postexposure Pro-phylaxis, 2001. MMWR 2001 / Vol. 50 / No. RR-11

59. Jack $A D$, Hall $A J$, Maine $N$, et al. What level of hepatitis B antibody is protective? J Infect Dis 1999; 179:489-92.

60. Bolyard EA, Tablan OC, Williams WW, et al. Guideline for infection control in healthcare personnel, 1998: Hospital Infection Control Practices Advisory Committee. Infect Control Hosp Epidemiol 1998; 19:407-63. 